\title{
SAÚDE ESCOLAR NO PARANÁ EM DOIS MOMENTOS HISTÓRICOS: NO COMEÇO DO SÉCULO XX E NO SÉCULO XXI
}

\author{
SCHOOL HEALTH IN PARANA IN TWO HISTORICAL MOMENTS: AT THE \\ BEGINNING OF THE $20^{\text {TH }}$ CENTURY AND IN THE $21^{\text {ST }}$ CENTURY
}

\section{SALUD ESCOLAR EN EL PARANÁ EN DOS MOMENTOS HISTÓRICOS: EN EL COMIENZO DEL SIGLO XX Y EL SIGLO XXI}

RENK, Valquiria Elita

valquiria.renk@pucpr.br

PUCPR - Pontifícia Universidade Católica do Paraná

\begin{abstract}
RESUMO O texto é um estudo comparativo de duas políticas de saúde escolar, no Paraná: uma dos anos de 1920 e outra do início do século XXI. A abordagem histórica apresenta como corpus documental os Relatórios de Governo, a revista O Ensino, da década de 1920, a legislação e os resultados do Programa de Saúde Escolar, implementado em 2007. Estas fontes presentam a posição oficial das políticas voltadas à prevenção, promoção e educação em saúde no espaço escolar. A análise tem como referência os estudos culturais de Foucault. Os resultados mostram que são políticas que incorporaram a saúde como um componente curricular, voltadas à mudança de condutas sociais e formação de hábitos saudáveis.
\end{abstract}

Palavras-chave: Educação; Saúde Escolar; Programa Saúde Escolar..

ABSTRACT The text is a comparative study of two school health policies, in Parana: one from the 1920s and the other one from the beginning of the $21^{\text {st }}$ century. The historical approach presents as documentary corpus the Government Reports, the magazine O Ensino, from the 1920s, the legislation and the School Health Program results, implemented in 2017. These sources present the official position of policies aimed at prevention, promotion and health education in the school environment. The analysis has as reference the cultural studies of Foucault. The results show that they are policies that incorporated health as a curricular component, aimed at changing social behaviors and forming healthy habits.

Key words: Education; School Health; School Health Program.

RESUMEN texto es un estudio comparativo de dos políticas de salud escolar, en el Paraná: una de los años de 1920 y otra de principios del siglo XXI. El enfoque histórico presenta como corpus documental los Informes de Gobierno, la revista La Enseñanza, de la década de 1920, la legislación y los resultados del Programa de Salud Escolar implementado en 2007. Estas fuentes 
presentan la posición oficial de las políticas dirigidas a la prevención, promoción y educación en salud en el espacio escolar. El análisis tiene como referencia los estudios culturales de Foucault. Los resultados muestran que son políticas que incorporaron la salud como un componente curricular, orientadas al cambio de conductas sociales y formación de hábitos saludables.

Palabras clave: Educación. Programa Salud Escolar. Salud Escolar.

\section{INTRODUÇÃO}

Este artigo aborda sobre a saúde escolar, no Paraná, em dois períodos: nos anos de 1920, quando se intensificam as políticas de higiene e saúde escolar, e em 2007, com a implantação do Programa Saúde na Escola (PSE) pelos Ministérios da Educação e da Saúde. Tem-se como hipótese que a escola foi e é um espaço de implementação das políticas de saúde, com a perspectiva de construir o futuro da população.

A preocupação com a saúde da população, a começar pela infância intensificou-se no Brasil, desde os anos de 1910, com o Movimento Sanitarista (HOCHMAN, 1998) ou Movimento Higienista (SOARES, 2001), que revelava a pobreza, a falta de saneamento e as doenças que acometiam a população dos sertões. Este movimento de caráter coletivo prescrevia hábitos higiênicos paralelamente ao movimento pela educação e saúde combinando com ideias eugênicas, que eram discutidas no país (BERTUCCI, 2015; PAGNI, 1997; MARQUES, 1994; MOTA, 2003; STEPAN, 2004, GOIS JÚNIOR; LUVISOLO, 2003).

Em 1920 foi criado foi criado Departamento Nacional de Saúde Pública que estabelecia diretrizes para a educação e saúde e em 1930 foi criado o Ministério da Educação e Saúde Pública (HOCHMAN, 1998; CARVALHO, 2000), que foi vislumbrado por médicos e educadores como a possiblidade de efetivação de uma política nacional em educação e saúde. No Paraná, em 1921, foi criado o Serviço de Inspeção Médico Escolar, para examinar os professores e os estudantes, detectar doenças contagiosas, verminoses e ensinar bons hábitos de higiene. 
No início do século $X X$, a saúde escolar estava atrelada aos preceitos de eugenia e higienismo ${ }^{1}$. As principais ações eram os cuidados com a higiene pessoal e do ambiente, a vacinação, a prevenção de moléstias contagiosas, doenças sexualmente transmissíveis, a prevenção de vícios e a formação de hábitos saudáveis. No início do século XXI, continuam sendo constatadas as precárias condições de saneamento básico, há o aumento dos casos de sífilis e de febre amarela, a imprensa e a escola fazem campanhas de combate aos mosquitos transmissores de doenças (dengue, zika, febre amarela e outros). $O$ Programa Saúde na Escola - PSE (Decreto n. 6.286 de 05 de dezembro de 2007) tem suas ações voltadas para a prevenção e a promoção da saúde, contribuindo para a formação integral dos estudantes da rede pública de ensino. (BRASIL, 2007). A escola continua sendo a instância de formação da infância e juventude saudável.

Este artigo se inscreve na perspectiva da História da Educação, cujo corpus documental é formado pela Revista O Ensino, publicada pela Inspetoria Geral do Ensino do Paraná, pelos Relatórios de Governo do Paraná dos anos de 1920 e pelo Decreto n. 6.286 de 05 de dezembro de 2007 que institui o PSE. Este conjunto de fontes documentais constitui indícios, representam a posição e o relato oficial sobre as políticas de saúde escolar e possibilitam ampliar o entendimento das políticas de saúde escolar (FARGE, 2009, CELLARD, 2008, CORSETTI;LUCHESI, 2010). A análise do corpus documental tem como referência os estudos do Foucault.

\section{APORTES HISTÓRICOS SOBRE A SAÚDE ESCOLAR}

\footnotetext{
${ }^{1}$ A eugenia pode ser entendida como o "estudo dos meios de controle social que podem beneficiar os prejudicar as qualidades raciais das gerações futuras, tanto física quanto mentalmente" (GALTON, 1988, p. 27- tradução livre). O movimento higienista propunha cuidar a população, educando-a e ensinando novos hábitos, seja na escola, no trabalho e nas ruas. Privilegiava o cuidado com a educação infantil, com a higiene e com a alimentação. O médico higienista era especializado em saúde pública e administração sanitária, prescrevia condutas higiênicas, tinha uma atuação social e também era um educador. Defendia a preservação da saúde (higienização) através da mudança de hábitos, via na Eugenia uma forma de 'melhorar' a pessoa, mas, os médicos eugenistas não aderiam as ideias de superioridade racial (KUHLMAN JR, 1998; PETRI, 2003).
} 
Os primeiros serviços de saúde escolar foram criados em Bruxelas (1874), Paris (1879), Japão (1903) e mais tarde foram incorporados pelo Brasil, Estados Unidos e Argentina. Eram semelhantes no atendimento aos alunos, nas especificações da arquitetura e mobiliário escolar para atender os preceitos de ergonometria e higiene, na avaliação e complementação nutricional, e também na triagem dos problemas de visão (SANCHO RAMIREZ, 1981). Neste sentido, Foucault (2012) discute que, a partir do final do século $\mathrm{XIX}$, o poder representa uma grande medicina social que se aplica à população a fim de controlar a vida, denominado de biopolítica.

No Brasil, as prescrições médicas no século XX foram impulsionadas pelos poderes da Ciência da Higiene, objetivando alavancar a cidadania, numa cruzada pela saúde, educação e civilidade (ROCHA, 2003). A aplicação das noções científicas relacionadas à higiene uniu-se no ideal de ordenamento urbano $^{2}$ que vinculou a escola às políticas de saneamento do espaço público e de higienização social que faziam parte de uma política mais ampla de enquadramento das camadas populares (SOUZA, 1998; IERVOLINO, 2000). No sentido eugenista-higienista, a saúde era pensada em termos físicos, mentais, intelectuais, sexuais e morais, sendo a escola um espaço fecundo para romper hábitos perniciosos e promover a transformação social (STEPHANOU, 1988).

Nos anos de 1920, a elite intelectual brasileira adotou a noção de que o 'branqueamento' da população poderia ser através dos modos, da saúde e da educação (SKIDMORE, 1976, SCHWARCZ, 1993, DÀVILA, 2006). Com a expansão da educação escolar, a difusão dos grupos escolares, havia a necessidade de fixação de hábitos de higiene e também da formação do sentimento de brasilidade (BENCOSTTA, 2005; ROCHA, 2003; VIDAL, 2005). A infância foi considerada como a depositária do futuro da nação e foi objeto das políticas de educação e saúde, que objetivavam o desenvolvimento da raça sadia, a partir do disciplinamento dos corpos, corrigindo desvios de

\footnotetext{
${ }^{2}$ Aliado a este processo em 1918 foi criado o Serviço de Prophylaxia Rural do Paraná, que desenvolveu projetos sanitários em 20 municípios do estado. Desenvolveu campanhas e projetos de saneamento tendo em vista a profilaxia de doenças endêmicas. Neste sentido, as reformas urbanas constituíram-se parte do projeto para sanear o meio rural (LIBLKIK, 2016).
} 
condutas. Os médicos e os professores tinham a missão de higienizar e moralizar individualmente cada sujeito.

A escola incorporou o discurso médico e implementou a vigilância dos aspectos físicos e higiênicos dos prédios escolares e dos estudantes por meio dos exames antropométricos, fisiológicos e físicos. Cabia a escola ensinar os saberes prescritos e também higienizar socialmente (MARQUES, 1994). A educação adotou "as fichas e os exames antropométricos, junto com as cadernetas sanitárias, no instrumento a partir do qual se toma toda e qualquer decisão sobre o futuro do escolar" (BAÑUELOS, 2000, p. 76). A escola tornavase uma espécie de 'aparelho de exame ininterrupto' (FOUCAULT, 2014).

\section{A SAÚDE ESCOLAR NO PARANÁ NOS ANOS DE 1920}

Nas primeiras décadas do século $X X$, as reformas urbanas e a medicalização das cidades, "através da desinfecção dos espaços públicos, limpeza dos terrenos baldios, drenagem de pântanos, alinhamentos das ruas, etc" (RAGO, 1985, p. 31), eram alvo de preocupação dos sanitaristas e também eram importantes medidas para sanear o meio rural.

Naquele período, os médicos paranaenses aderiram ao discurso higienista e civilizador, divulgando seus ideários na Revista Médica do Paraná, e na Revista O Ensino, tornando-se os propagandistas da higiene, da contenção dos flagelos e da regeneração nacional (LAROCCA; MARQUES, 2010, JANZ JUNIOR, 2011). Estes manuais visavam delinear novas práticas de higiene, a reconfiguração do espaço escolar e a profilaxia das doenças que acometiam os escolares. As noções de higiene passaram a ser um componente curricular, nos Códigos do Ensino do Estado do Paraná de 1915, de 1917 e no $4^{\circ}$ ano da Escola Normal. O Inspetor de Ensino Cesar P. Martinez, "tinha convicção de que normas de bem-viver com saúde, ensinadas aos professores de modo a desempenhar a contento seus papéis de mestres, reverteriam nos hábitos dos alunos (...)" (MARQUES; FARIAS, 2007, p.127).

Em 1920, a Inspetoria Geral do Ensino organizou o Curso Elementar de Higiene, destinado aos professores para torna-los divulgadores da higiene moderna (ARAÚJO, 1921, LAROCCA, MARQUES, 2010). Os médicos eram os 
docentes do curso, ensinavam sobre os cuidados e asseio das mãos, unhas, dentes, olhos, as moléstias da pele, do couro cabeludo e também sobre a higiene das roupas e da escola. Os professores deveriam identificar os estudantes com verminoses, anemias, tuberculose, epidemias (sarampo, varicela, coqueluche e outras), que eram fatores de evasão ou baixo rendimento escolar. Para as autoridades não era possível "compreender a Hygiene separada da escola" (PARANA 1923, p. 17- grafia original).

A formação moral também era objeto de ensino, pois a "vadiação era um grande mal do nosso povo" (PARANA, 1921, p. 26). O professor ensinava sobre os males que o álcool causava na saúde física e moral, nas vantagens de uso de sapatos, acreditando na "sua redempção, que é a nossa independência - a hygiene e a escola dêm tudo quanto podem dar (...) e tendo a frente para o combate em campo aberto, o médico e o professor num perfeito apostolado" (PARANA, 1923, p. 25 grafia original). Outras medidas como as aulas de educação moral e cívica, de educação física escolar, os trabalhos manuais, moldariam socialmente os estudantes para tirá-los do caminho dos vícios e torná-los sujeitos produtivos.

O Serviço de Inspeção Médico Escolar (Lei 2.095, de 31 de março de 1921) deveria atender "[...] as escolas e grupos, examinando a miúdo seus alunos e professores" (PARANÁ, 1921, p. 24, MUNHOZ, 1924). Os médicos precisavam ser especialistas em medicina infantil e higiene escolar. Suas obrigações eram: visitar a escola todos os dias, examinar os estudantes, inspecionar as condições de higiene do edifício, fazer o registro sanitário dos escolares, vacinar contra febre amarela e difteria, colher material para 0 laboratório e fiscalizar o ensino de higiene (PARANA, 1924a, PARANÁ, 1921).

As escolas do Paraná eram muitos diferentes entre si (desde os grupos escolares até as escolas isoladas), estavam localizadas em áreas urbanas e rurais e atendiam crianças de diferentes classes sociais. O professor era importante auxiliar no serviço de profilaxia, ao ensinar lições sobre malária, tuberculose, e outras que deveriam mudar hábitos, mesmo daquelas consideradas mais refratárias aos preceitos científicos. O ensino de hábitos 
saudáveis revelava uma preocupação com a formação do trabalhador para torná-lo apto ao trabalho.

\section{SAÚDE ESCOLAR: UMA PREOCUPAÇÃO QUE PERSISTE}

A temática de saúde escolar não se esgota nas primeiras décadas do século $\mathrm{XX}$, mas, persiste até os dias atuais, considerando-se os novos contextos sociais. Nos anos de 1950/1960 a saúde escolar fazia as triagens audiovisuais e auditivas, a subnutrição passou a ser enfrentada com a oferta da merenda escolar e o rendimento escolar passou a ser considerado também como um problema de distúrbio neurológico (SILVA e ARELALO, 1987).

Desde a década de 1960, a UNESCO e a Organização Mundial de Saúde trabalham com questões de saúde escolar, com a publicação do manual Planning for Heath Education in Schools ${ }^{3}$, com a expertise da tecnologia e conhecimentos de países desenvolvidos para os países em desenvolvimento (ASTHON, 1991).

Nos anos de 1970, os exames físicos em massa e as fichas padronizadas para o registro da saúde, para levar os estudantes a desenvolver hábitos saudáveis quanto á higiene pessoal, alimentação, prática desportiva, ao trabalho e ao lazer. Neste sentido Foucault (2014) analisa que as técnicas e os métodos de disciplina aplicados sobre o corpo permitem o controle das operações em um jogo de forças, impondo a relação docilidade-utilidade. A Lei de Diretrizes e Bases da Educação- Lei 5692-71 (BRASIL, 1971) introduziu formalmente no currículo escolar a saúde, sob o nome de Programa de Saúde, com o objetivo de "levar a criança e o adolescente ao desenvolvimento de hábitos saudáveis quanto à higiene pessoal, alimentação, prática desportiva, ao trabalho e ao lazer, permitindo-Ihes a sua utilização imediata no sentido de preservar a saúde pessoal e a dos outros" (Parecer CFE, n. 2664/74, apud MINISTÉRIO DA EDUCAÇÃO, 2001, p. 258). Persiste a inculcação de hábitos de individuais de higiene, objetivando a aptidão para o trabalho. 
No final do século XX, a Organização Mundial da Saúde - OMS, pautou suas ações na promoção da saúde, no ambiente saudável, incluindo a educação em saúde no Projeto Político Pedagógico (LEGER, NUTBEAM 2000). Também produziu documentos, projetos e modelos na busca da saúde em ambiente escolar, objetivando basicamente os países pobres, tais como a Rede Latino Americana de Escolas Promotoras de Saúde e a Iniciativa Global de Saúde Escolar (WHO, 1996, OPAS, 1996). Também publicou uma série de técnica sendo o primeiro volume sobre parasitoses, seguindo de outros volumes sobre HIVIAIDS, nutrição, prevenção de doenças e outros (WHO et all, 2000), que não são epidemias, mas doenças que subtraem as forças e diminuem o tempo de trabalho cujo impacto econômico é maior que a prevenção ou tratamento, como analisa Foucault (1999). O PSE tem suas ações ancoradas nestas orientações da OMS de promoção e educação em saúde.

Em 1996 entrou em vigor a Lei de Diretrizes e Bases da Educação Nacional, LDB, Lei 9394-96, que não aborda especificamente a saúde escolar, mas, é um tema transversal nos Parâmetros Curriculares Nacionais. A escola está articulada com outras instituições como a Organização Panamericana em Saúde (OPAS), Programas de Vigilância em Saúde, Saúde da Família, Sistema Único de Saúde (SUS), cujas ações iniciam por identificar os riscos à saúde existente no ambiente escolar e eliminá-los, vinculada ao PSE (BRASIL, 2009)

\section{O PROGRAMA SAÚDE NA ESCOLA - PSE}

O Programa Saúde na Escola-PSE criado pelo Decreto n. 6.286 de 2007, é uma política intersetorial dos Ministérios da Saúde e da Educação, voltada aos estudantes da educação pública para promover saúde e educação integral. A adesão ao PSE é municipal, envolvendo as escola e rede básica de saúde, nas ações de avaliação, promoção da saúde e formação das equipes de gestores de educação e saúde (BRASIL, 2007, PARANÁ, 2017). A intersetorialidade do PSE é uma política de gestão, mas encontra problemas na sua execução, especialmente com a falta de integração entre as equipes de 
saúde e a das escolas. Os profissionais de saúde relatam que há muita burocracia na gestão do PSE, "que a saúde precisa ir à escola, mas estamos paralisados" (PENSO et all, 2013, p. 548). Fernandes et all (2005) relatam que os professores se mantêm distanciados do tema saúde, por falta de conhecimento. Também identificam algumas situações que podem colocar o PSE em risco, como: a qualificação continuada aos profissionais da educação não está correspondendo as expectativas, a sobrecarga de trabalho dos professores deixa a saúde em segundo plano e identificam que há resistência na execução por parte da escola ou dos profissionais de saúde

O Ministério da Saúde reconhece que a escola é o espaço privilegiado de formação em saúde e educação para a saúde. Para a sua efetivação publica os Cadernos de Atenção Básica e em conjunto com a OPAS, Saúde da Família e o SUS publica o Passo a Passo - PSE, cujo objetivo é "promover a gestão do programa, com as equipes de saúde da família e a equipe pedagógica da escola”. (BRASIL, 2009, p. 17). Assim, nestes periódicos há uma dimensão pedagógica, sendo dispositivos educativos pois apresentam o discurso e as medidas administrativas de operacionalização do PSE (FOUCAULT 2012).

No estado do Paraná, um dos critérios para a escola participar do PSE é ter ao menos $50 \%$ dos estudantes matriculados pertencentes a famílias beneficiárias do Programa Bolsa Família (PARANÁ, 2017). Esta política se insere num conjunto de intervenções para baixar a morbidade e maximizar as forças para se tornarem sujeito saudáveis e produtivos (FOUCAULT, 1999). Apesar do PSE não informar de forma clara a preocupação com a formação do cidadão saudável e futuro trabalhador, o tema transparece nos seus objetivos e nas ações propostas.

As Secretarias da Educação e da Saúde do Estado do Paraná e da Prefeitura Municipal de Curitiba trazem poucas informações sobre o PSE, evidenciando a execução parcial da política, a pouca importância atribuídas pelas instituições a esta política e os processos de resistência desenvolvidos pelos sujeitos envolvidos. Não há informações sobre a quantidade de escolas, profissionais e estudantes atingidos pelo PSE, no site do governo do Paraná. 
Entre os resultados do PSE na rede pública de ensino de Curitiba, em 2017, há a informação da universalização do atendimento oftalmológico, nutricional e biométrico e o enfoque na prevenção de doenças, sem apresentar dados numéricos. Também há a informação da capacitação dos profissionais de Saúde e Educação para avaliar os estudantes e encaminhá-los para o tratamento adequado. Neste sentido, o diagnóstico faz parte da patologização da educação, para medicalizar e justificar o fracasso escolar e o estudante que é considerado "desviante" passa pelas técnicas de disciplinamento, investimentos médicos, análise, medidas para sua "regeneração" ou “aceitação” (TEIVE; ABUD, 2014, p. 132).

As escolas que aderem ao PSE precisam incorporar a temática saúde no seu Projeto Político Pedagógico e nas ações do cotidiano da escola. Neste sentido, a saúde é um dispositivo pedagógico, legitimado através pela presença dos profissionais da saúde na escola para o autocontrole, cuidado dos corpos, com a "consciência sanitária" dos "regimes higiênicos" (FOUCAULT, 2002, 2014).

\section{AS POLÍTICAS DE SAÚDE ESCOLAR EM DOIS MOMENTOS HISTÓRICOS}

Considerando que a formação saudável dos escolares fez parte das políticas educacionais, buscou-se nas fontes documentais oficiais as ações formuladas para implementação da saúde escolar, em dois momentos distintos, conforme pode ser observado no Quadro1.

QUADRO 1 - Comparativo das Ações em Saúde Escolar: Década de1920 e 2007

\begin{tabular}{|l|l|}
\hline Ações Saúde nos anos 1920 no Paraná & Ações de saúde do PSE \\
\hline $\begin{array}{l}\text { 1 Inspeção Médico Escolar } \\
\text { Purso de Higiene para Professores }\end{array}$ & $\begin{array}{l}\text { Formação continuada dos profissionais de } \\
\text { educação e saúde envolvidos, Inserção da } \\
\text { saúde no Projeto Político Pedagógico - PPP }\end{array}$ \\
\hline $\begin{array}{l}\text { Hexames antropométricos } \\
\text { Higiene corporal, das vestes dos olhos, das dos alimentos } \\
\text { Assistência Dentária Escolar }\end{array}$ & $\begin{array}{l}\text { Avaliação Clínica e Psicossocial - Ficha } \\
\text { Antropométrica, Avaliação auditiva, Avaliação } \\
\text { nutricional; promoção da alimentação } \\
\text { saudável. Avaliação oftalmológica. Avaliação } \\
\text { da saúde e higiene bucal }\end{array}$ \\
\hline $\begin{array}{l}\text { 3 Educação moral } \\
\text { Escotismo }\end{array}$ & $\begin{array}{l}\text { Promoção da cultura da prevenção no âmbito } \\
\text { escolar, Protagonismo juvenil, Prevenção e } \\
\text { redução do consumo de álcool, controle de }\end{array}$ \\
\hline
\end{tabular}




\begin{tabular}{|l|l|}
\hline & tabagismo e outros fatores de risco de câncer \\
\hline 4 Atividade física e educação física escolar; & $\begin{array}{l}\text { Atividade física e saúde; combate ao } \\
\text { sedentarismo, atividades físicas }\end{array}$ \\
\hline $\begin{array}{l}5 \text { Profilaxia e vacinação: Impaludismo, } \\
\text { verminoses, tuberculose e sífilis }\end{array}$ & $\begin{array}{l}\text { Atualização e controle do calendário vacinal; } \\
\text { detecção de tuberculose, hanseníase, } \\
\text { malária, asma. }\end{array}$ \\
\hline 6 Combate à sífilis & $\begin{array}{l}\text { Promoção da saúde sexual e da saúde } \\
\text { reprodutiva, educação para a saúde sexual e } \\
\text { reprodutiva }\end{array}$ \\
\hline
\end{tabular}

Fonte: PARANÁ, 1920, PARANÁ, 1921a, PARANÁ, 1923a, PARANÁ, 1924a, BRASIL, 2007.

Os dados apresentados no Quadro 1 demonstram que em quase cem anos, a saúde é uma questão social e a escola é espaço onde o Estado centra suas ações voltadas para a formação da população, a iniciar pela infância escolar (GADELHA, 2014). A escola continua sendo um lugar de vigilância e controle, através de exames físicos, que esmiúçam o corpo humano e projetam nele a perspectiva da saúde, como indicam os dados do Quadro 1. As duas políticas objeto deste estudo objetivam atingir a população de baixa renda, no sentido de transformar hábitos e produzir sujeito saudáveis e aptos para o trabalho.

A seguir serão analisados os elementos das duas políticas de educação em saúde, conforme a numeração estabelecida no Quadro 1.

1 - As ações de formação de professores em curso de Higiene eram pontuais na escola (1920/30) e o PSE prioriza a formação continuada para profissionais de educação e profissionais de saúde. A dimensão pedagógica da saúde escolar está na inserção do tema no PPP, sinalizando que o poder disciplinar está presente no cotidiano das escolas, com a internalização de hábitos de higiene e também mudança de atitude. No século $X X I$, não se observa a inserção dos médicos no ambiente escolar e as ações executadas são mais pontuais como, exemplo o envolvimento dos estudantes em campanhas (combate à Dengue, 'Zika Zero', vacinação dos estudantes contra o HPV, Semana da Saúde).

2 - Enquanto nos anos de 1920/30 o Brasil era um país rural, havia a necessidade de ações voltadas para a necessidade de instalações sanitárias, o uso de calçados, o hábito de lavar as mãos e outros (MEZZOMO, 1990, 
LIBLIK, 2016), para formar hábitos de higiene pessoal e mudança de comportamentos Os estudantes eram submetidos aos exames físicos e de saúde, de forma contínua, demonstrando a vigilância sobre seus corpos. As fichas antropométricas e de avaliação de saúde, esmiúçam, detalham e fazem o 'esquadrinhamento' do corpo (FOUCAULT, 2014).

O PSE prioriza a avaliação, os exames e as fichas médicas permitem o registro e o controle do corpo, as manifestações de doenças, "detalham as minúcias da anatomia corporal, evidenciam o investimento médico sobre o corpo biológico, psicológico, fisiológico, numa anatomia corporal prescrita pelo exame e tecnologias pedagógicas" (TEIVE;ABUD, 2014, p. 132). O preenchimento de fichas e relatórios médicos evidenciam que no período do início dos séculos $\mathrm{XX}$ e $\mathrm{XXI}$, os detalhes e as minúcias da anatomia corporal são tratados pela escola com prescrições dietéticas, nutricionais e médicas, contemplando a biopolítica da sociedade perfeita, através da regulação do corpo social (ORTEGA, 2003).

A higiene bucal e o acesso aos serviços de atendimento odontológicos fazem parte das políticas de saúde escolar, mostrando que a saúde dentária ainda é uma realidade distante da maioria da população brasileira.

O PSE focaliza as ações na nutrição e no ensino de hábitos alimentares saudáveis, em decorrência grande número de casos de obesidade infanto juvenil, com suas consequências para a saúde. Batista (2017) analisa que uma em cada três crianças estão com sobrepeso e uma ação que pode ser implementadas nas escolas, é a inserção de alimentos saudáveis no cardápio escolar. Neste sentido, as ações preventivas são técnicas de intervenção social com efeitos reguladores sobre a população (FOUCAULT, 1999).

3- A saúde moral dos jovens era e continua sendo uma preocupação escolar e uma questão social. Os jovens estão mais expostos a fatores de risco para a saúde como o consumo de álcool, de cigarros, sedentarismo (CAMPOS et all, 2013). Polonia; Dessen (2005) analisam que o investimento na população com 15 anos ou menos demonstra a incorporação de novos comportamentos na vida adulta. Raposo (2009) critica as ações pedagógicas do PSE, especialmente no que se refere a sexualidade dos jovens, destacando 
que em sua maioria ficam restritas a palestras ou abordagens com distribuição de preservativos. A participação dos jovens nas decisões sobre a sua vida ou seu futuro também exigem uma participação mais efetiva, através do protagonismo juvenil.

4 As atividades físicas e a educação física trazem o discurso de uma vida mais saudável, prevenção de doenças, fator disciplinador e moralizador. "A disciplina 'fabrica' os corpos, ela é técnica específica de um poder que toma os indivíduos ao mesmo tempo como objetos e como instrumentos de seu exercício" (FOUCAULT, 2014, p. 153). A educação física escolar justifica-se para combater os males decorrentes da obesidade e do sedentarismo. Foucault (2012) analisa que o investimento no corpo através de ginásticas e exercícios demonstra como o poder é exercido sobre os corpos das crianças.

Assim, no início do século XX a educação física era necessária para formar a pessoa com maior resistência física e disciplina para o trabalho. No PSE, as atividades físicas justificam-se para combater o sedentarismo, realização de atividades de lazer e também como um ideário de vida saudável (LOVISOLO, 2002).

5 No século $X X I$ os insetos e mosquitos não foram debelados $e$ continuam transmitindo doenças, como indicam o aumento nos casos de malária e febre amarela (BRASIL, 2016), que têm como consequências diminuição do rendimento do trabalho que traz custos econômicos e invocando a necessidade da medicalização da população (FOUCAULT, 2002, 1999). O PSE propõe a vacinação como medida profilática e também o diagnóstico precoce de doenças como a asma, a hanseníase e a tuberculose. Portanto, pode-se considerar que a população é um objetivo, um fim e um instrumento de governo e cabe a ele criar os meios e as técnicas para "agir indiretamente sobre a saúde da população" (FOUCAULT, 2012, p. 425).

A sexualidade é um tema recorrente nas duas políticas deste estudo. Nos anos de 1920/30, a degenerescência punia o corpo do indivíduo devido ao seu comportamento sexual e os discursos médicos referentes a saúde abordavam sobre a profilaxia das doenças, os cuidados com a infância e também com a sexualidade dos adolescentes (MEZZOMO, 1990, LIBLIK, 
2016). Foucault (1999, p. 300) analisa que a sexualidade está na "encruzilhada do corpo e da população, ela depende da disciplina e também da regulamentação". A sífilis era uma doença combatida no início do século XX, e ainda não foi debelada. Houve um aumento em $27,8 \%$ no número de casos de sífilis adquirida em adultos de 2015 para 2016, no Brasil (BRASIL, 2017) demonstrando que as ações preventivas no espaço escolar, não estão surtindo efeito, assim como uma educação em saúde está sendo ineficaz em pleno século XXI. O PSE privilegia a educação sexual e reprodutiva e a prevenção às doenças sexualmente transmissíveis, como AIDS ou mesmo a educação para a saúde sexual e reprodutiva, assim como os casos de gravidez na adolescência, mostrando que a sexualidade dos jovens ainda é uma questão controlada pelo Estado. Mudou o discurso, mas, não o controle sobre o corpo dos jovens.

\section{CONSIDERAÇÕES FINAIS}

Para a formação da população saudável, no decorrer do período em análise por este artigo, identificou-se que a escola e os saberes escolares são usados para disseminar práticas sociais, que irão reverberar em mudanças de hábitos na sociedade. A persistência de problemas de saúde e saneamento básico faz do espaço escolar o lugar da ação do Estado nas políticas de saúde para a população, a começar pela infância. Pode-se reconhecer nestes atos o biopoder como a proposta de desenvolvimento saudável da população.

Existem muitas semelhanças nas políticas analisadas nesta pesquisa, como a formação, qualificação e treinamento dos professores para examinar e identificar doenças nos estudantes e encaminhá-los para tratamento, a avaliação clínica no modelo de fichas, o controle da vacinação, a promoção da saúde sexual e reprodutiva, a saúde moral a formação e mudança de hábitos de vida e de saúde.

Atualmente a escola ainda é o espaço da ação do Ministério da Saúde, tais como a vacina contra o vírus HPV para adolescentes, campanhas educativas para a prevenção e combate ao mosquito transmissor da dengue, entre outras, com alcance social. 
Atitudes sociais consideradas inadequadas e que possam prejudicar a saúde, tais como o uso do álcool e outras drogas, tem na escola, a prevenção inscrita nos saberes e nas ações do Projeto Pedagógico, tornando-se dispositivos pedagógicos. Os argumentos são semelhantes nas duas políticas analisadas: a formação do cidadão produtivo, passa pela saúde, pela prevenção aos vícios e o desenvolvimento de hábitos saudáveis.

Na década de 1920, no Paraná, os médicos entraram na escola com a higiene e saúde escolar. A racionalidade científica embasava as ações para a formação e conformação da população dentro de uma perspectiva mais abrangente. No século XXI, o ideário de saúde da população através da saúde escolar ainda existe, mas, sem o protagonismo médico, pois a proposta do PSE está voltada à educação em saúde, prevenção de doenças centrada em fatores biológicos e de saúde, negligenciando os aspectos econômicos, sociais e políticos do adoecer. O controle da saúde de cada estudante é anotado em fichas de avaliação e os encaminhamentos são feitos aos postos de saúde, mostrando o distanciamento do médico no ambiente escolar.

As duas políticas de saúde escolar indicam que os exames, o escrutínio, a vigilância dos corpos são formas de ação incorporadas no cotidiano escolar que buscam educar e reorganizar a sociedade. Atualmente os saberes sobre a saúde escolar são componentes curriculares, incorporados no Projeto Pedagógico, executados em Semanas de Saúde, ou ações pontuais, preventivas e eventos. O ensino da higiene e a promoção da saúde nas escolas contribuem para a produção de dispositivos de atenção ao cuidado com o asseio, modo de viver, comportar-se e na produção do sujeito saudável e aceitável na sociedade.

\section{VALQUIRIA ELITA RENK}

Mestre e Doutora em Educação. Professora Permanente do Programa de PósGraduação em Bioética e Programa de Pós-Graduação em Direitos Humanos e Políticas Públicas da PUCPR. Líder do Grupo de Pesquisa Bioética e Educação. Membro da Sociedade Brasileira de Bioética e Sociedade Brasileira de História da Educação

\section{REFERÊNCIAS}


ARAUJO, HCS. Curso de Hygiene Elementar. Archivos Paranaenses de Medicina.v. 1 n.11 p. 373,1921

ASTHON, J.The helthy Cities Project: A challenge for health education. Health Educacion. v. 18 p. 39-48, 1991.

BAÑUELOS, A .T. La higiene escolar: um campo de conocimento disputado. Áreas: Revista de Ciencias Sociales, n. 20, p. 73-94, 2002.

BATISTA, $M$ da $S$, et all. Ações do Programa Saúde na Escola e da alimentação escolar na prevenção do excesso de peso infantil: a experiência no município de Itapevi, São Paulo, 2014. Epidemiol. Serv.Saúde. Brasília v.26 n.3 p.569-578 jul- set 2017

BENCOSTTA, M, L.A. Desfiles patrióticos: memória e cultura cívica dos grupos escolares em Curitiba (1903-1971) In. VIDAL, D. G.(org) Grupos escolares: cultura escolar primária e escolarização da infância no Brasil (1893-1971). Campinas: Mercado das Letras, 2005.

BERTUCCI, L.M. A Escola Primária na Revista Médica do Paraná. VIII Congresso Brasileiro de Educação. Maringá, Anais, VIII CBHE, 2015;

CAMPOS, H. M.; SCHALL, V. T.; NOGUEIRA, M. J. Saúde sexual e reprodutiva de adolescentes: interlocuções com a pesquisa nacional de saúde do escolar (PeNSE). Saúde em Debate, Rio de Janeiro: Centro Brasileiro de Estudos de Saúde - Cebes, v. 37, n. 97, p. 336-346, abr./jun. 2013.

CARVALHO, M.M.C.DE. Reformas da Instrução Pública. In LOPES, E.M.T;FARIA FILHO, L. M. de; GREIVE, C.G. (org) 500 anos de Educação no Brasil. Belo Horizonte: 2000, p. 225-251

CELLARD, A. A análise documental. In: POUPART, J, et al. A pesquisa qualitativa: enfoques epistemológicos e metodológicos. Petrópolis: Vozes, 2008, p. 295- 315.

CORSETTI, B.; LUCHESE, T. A . Educação e instrução na Província do Rio Grande do Sul. In: GONDRA, J. G.; SCHNEIDER, O. (Org.). Estado e instrução nas províncias e na corte imperial. Vitória: EDUFES, 2010, p. 453- 485.

FARGE, A. O sabor do arquivo. São Paulo: EDUSP, 2009.

D'ÁVILA, J. Diploma de brancura. Política social e racial no Brasil - 1917-1945. São Paulo: Unesp, 2006.

FERNANDES, M.H, ROCHA, V.M, SOUZA, D.B. A concepção sobre saúde do escolar entre professores do ensino fundamental ( $1^{a}$ a $4^{a}$ séries). Rev Hist Cienc Saúde - Manguinhos v.12 n 2, p. 283-291, 2005. Disponível em: 
http://www.scielo.br/scielo.php?pid=S0104-

59702005000200004\&script=sci arttext. Acesso em 14 set 2017

FOUCAULT, M. Microfísica do Poder. São Paulo: Graal, 2012. p. 364-382.

. História da sexualidade. São Paulo: Graal, 2002. v. 3.

. Vigiar e Punir. Nascimento da prisão. $42^{\mathrm{a}}$ ed. Petrópolis, RJ: Vozes, 2014. . Em defesa da sociedade. São Paulo: Martins Fontes, 1999.

GADELHA, S. Biopolítica, governamentabilidade e educação. Introdução e conexões a partir de Michel Foucaul. Belo Horizonte: Autêntica, 2014.

GALTON, F. Herencia y engenésia. Madri: Alianza Editorial, 1988.

GOIS JÚNIOR, E; LUVISOLO, H,R. Descontinuidades e continuidades do Movimento Higienista no Brasil do século XX. Ver. Bras. Ciência do Esporte. Campinas, v. 25 n. 1, p. 41-54, set. 2003

HOCHMAN, G. A era do saneamento. São Paulo: Hucitec, 1998.

IANZ JÚNIOR, D. C O valor da eugenia e do higienismo no discurso médico curitibano no início do século XX. Cordis. Historia, Corpo e Saúde, n. 7, jul-dez, p. 87-120, 2011.

IERVOLINO, S.A .Escola promotora da saúde: um projeto de qualidade de vida.São Paulo: 2000. (Monografia. Faculdade de Saúde Pública da Universidade de São Paulo)

LAROCCA, L. M; MARQUES, V.R.B. Higieniza, cuidar e civilizar. O discurso médico para a escola paranaense (1920-1937) Interface comunicação saúde educação v 14 n 34 p. 647-60 jul-set 2010.

KUHLMANN Jr., M. Infância e educação Infantil: uma abordagem histórica. Porto Alegre: Mediação, 1998.

LEGER,L.H.S; NUTBEAM, D. Research into Health Promoting Schools. Journal of School Health n. 70: p. 257-9, 2000.

LIBLIK, C.S.da F. K. Atuação médico sanitária nos municípios rurais do Paraná (1918-1930). Intelléctus, ano 15, n. 1, p. 55-78, 2016.

LOVISOLO, H. Atividade física e saúde: uma agenda sociológica da pesquisa. In MOREIRA, W.W.(org). Esporte como qualidade de vida. Piracicaba: UNIMEP, 2002. 
MARQUES, V.R.B. A medicalização da raça: médicos, educadores e discurso eugênico. Campinas: Editora da UNICAMP, 1994.

MARQUES, V.R.B; FARIAS, F.C.S.A . A inspeção médico-escolar no Paraná dos anos de 1920:0 apostolado de médicos e professores. In. DINIS, N.F; BERTUCCI, L.M. Mútiplas faces do Educar: processos de aprendizagem, educação e saúde, formação docente. Curitiba: Ed. UFPR, 2007.

MEZZOMO, C.R. Médico e educadores: a disciplinarização da família curitibana (1890-1930). Dissertação (Mestrado em Historia), UFPR, 1990, p.231

MOTA, A. Quem é bom já nasce feito. Rio de Janeiro: DP\&A, 2003.

MUNHOZ, Milton. A saúde pela educação. Revista Médica do Paraná. v.3 n. p. 11-18, 1924.

ORTEGA, F. Biopolíticas da saúde: reflexões a partir de Michel Foucault, Agnes Heller e Hannah Arendt. Interface-Comunic, Saúde, Educ., v.08, n,14,p.09-20.set, 2003.

PAGNI, P. A. A prescrição dos exercícios físicos e do esporte no Brasil (18501920): cuidados com o corpo, educação física e formação moral. In: FERREIRA NETO (Org.). Pesquisa histórica na educação física. Vitória: CEFD/UFES, 1997. 2 v. p. 59-82.

POLONIA, A. da C.; DESSEN, M. A. Em busca de uma compreensão das relações entre família e escola: relações família-escola. Psicologia Escolar e Educacional, Campinas: Associação Brasileira de Psicologia Escolar e Educacional, v. 9, n. 2, dez. 2005, p. 303-312.

PENSO, M.A; BRASIL, K.C.T.R; ARRAIS, A.R; LORDELO, S.R. A relação entre saúde e escola: a percepções dos profissionais que trabalham com adolescentes na atenção primária à saúde no Distrito Federal. Saúde Soc. São Paulo v.22, n.2, p 542-553, 2013.

PETRI, R. Psicanálise e educação no tratamento da psicose infantil: quatro experiências institucionais. São Paulo: Annablume, 2003.

RAGO, M. Do cabaré ao lar: a utopia da cidade disciplinar, Brasil 1892-1930. Rio de Janeiro: Paz e Terra, 1985.

RAPOSO, C.A. Política de Atenção Integral à Saúde do Adolescente e Jovem: uma perspectiva de garantia de direito à saúde? Revista em Pauta. Rio de Janeiro, v. 6, n. 23, p 117-138, 2009. 
ROCHA, H. H. P. A higienização dos costumes: educação escolar e saúde no projeto do Instituto de Hygiene de São Paulo (1918-1925). Campinas: Mercado de Letras, 2003.

SANCHO RAMIREZ, F. La medicina Escolar em el mundo.Rev. Española de Medicina e Higiene Escolar ,1981, v. 35, p 139-154.

SILVA T.R.N e ARELALO, L.R.G. Orientações Legais na área de Currículo nas esferas federal e estadual a partir da lei 5.692/71. Cad. Cedes, v. 1987; p. 1321.

SOARES, C.L. Educação Física, raízes europeias e Brasil. Campinas: Autores Associados, 2001.

SOUZA, R.F. Templos de civilização: a implantação da escola graduada no estado de São Paulo (1900-1910). São Saulo: UNESP1998

SKIDOMRE, T,E. Preto no branco raça e nacionalidade no pensamento brasileiro. Rio de Janeiro: Paz e Terra, 1976

STEPHANOU,M. Currículo escolar e educação em saúde.um pouco da história do presente.In MEYER , D.E.E (org). Saúde e sexualidade na escola. Porto Alegre: Mediação, 1998.

SCHWARCZ, L.M. O espetáculo das raças. São Paulo: Companhia das Letras, 1993

STEPAN, N,L. Eugenia no Brasil 1917-1940. In. HOCHMAN, G; ARMUS, D. (orgs). Curar, controlar, cuidar. Rio de Janeiro, FioCruz, 2004 p. 331-191.

TEIVE, G. M. G.; ABUD, C.C.R. Biopolítica e biossociabilidade na escola: O programa Saúde Escolar. Debates em Educação. v. 6, n. 12, Jul./Dez. 2014.

VIDAL, D. G.(org) Grupos escolares: cultura escolar primária e escolarização da infância no Brasil (1893-1971). Campinas: Mercado das Letras, 2005.

WHO WORLD HEALTH ORGANIZATION. The world health report 1996 Fighting disease, fostering development. WHO: Genebra, 1996. Disponível em https://www.who.int/whr/1996/en/. Acessado em 12 nov 2017

WHO/ WORLD HEALTH ORGANIZATION et all Focusing Resources on Effective School Health: a FRESH Start to Enhancing the Quality and Equity of Education. Dakar: WHO/UNESCO/UNICEF/Word Bank, 2000.

\section{Documentos}


BRASIL. Lei de Diretrizes e Base de 1971 - Lei 5692/71 de 11 de agosto de 1971. Fixa Diretrizes e Bases para o ensino de $1^{\circ}$. E $2^{\circ}$. Graus e dá outras providências. Brasília: Diário oficial da União, 12 ago.1971.

BRASIL. Lei 9394 de 20 de dezembro de 1996. Estabelece as diretrizes e bases da educação nacional. Brasilia: Prediência da República, 1996. Isponível em http://www.planalto.gov.br/ccivil 03/LEIS/L9394.htm. Acessado em 08 abr 2016.

BRASIL. Decreto n. 6.286 de 2007. Institui o Programa Saúde na Escola - PSE, e dá outras providências. Disponível em http://www.planalto.gov.br/ccivil 03/ ato2007-2010/2007/decreto/d6286.htm.

Acessado em 08 abr 2016

BRASIL. MINISTÉRIO DA SAÚDE. Secretaria de Atenção à Saúde. Departamento de Atenção Básica. Saúde na escola. Brasília: Ministério da Saúde, 2009.

BRASIL. MINISTÉRIO DA SAÚDE. Secretaria de Atenção à Saúde. Departamento de Atenção Básica. Instrutivo PSE / Ministério da Saúde. Secretaria de Atenção à Saúde. Departamento de Atenção Básica. Brasília: Ministério da Saúde, 2011.

BRASIL. MINISTÉRIO DA SAÚDE. Políticas de Saúde. Projeto promoção da Saúde. As Cartas de Promoção da Saúde. Brasília, DF, 2002.Disponível em WWW.saúde.gov.br/bvs/publicacoes/cartas promoção.pdf. Acesso em 2 ago $\underline{2016}$

BRASIL. MINISTÉRIO DA SAÚDE. Notícias. Malária doença endêmica - em maior número na região norte, segundo o Ministério da Saúde em $2015 \mathrm{Em}$ 2015, foram notificados cerca de 143 mil casos. Brasília< Ministério da Saúde, $2016 . \quad$ Disponível em: http://portalsaude.saude.gov.br/index.php/cidadao/principal/agenciasaude/23368-brasil-registra-menor-numero-de-casos-de-malaria-nos-ultimos35-anos. Acessado em 20 ago 2016.

BRASIL. MINISTÉRIO DA SAÚDE. Notibrás. Brasília, 2017. Disponível em https://www.notibras.com/site/ministerio-da-saude-alerta-sobre-o-aumento-decasos-de-sifilis/. Acessado em 01 nov 2017

BRASIL. MINISTÉRIO DA EDUCAÇÃO. Parecer CFE, n. 2664/74. Brasília: MINISTÉRIO DA EDUCAÇÃO, 2001, p. 258

OPAS. ORGANIZAÇÃO PANAMERICANA DE SAÚDE. Manual De Vigilância Da Saúde De Populações Expostas a Agrotóxicos. Brasília: Ministério da Saúde, 1996. 
PARANÁ. Relatório de Governo. Curitiba: Departamento Estadual de Arquivo Público, 1921.

PARANÁ. Relatório de Governo. Curitiba: Departamento Estadual de Arquivo Público, 1922.

PARANÁ. Relatório de Governo. Curitiba: Departamento Estadual de Arquivo Público, 1923.

PARANÁ. Relatório de Governo. Curitiba: Departamento Estadual de Arquivo Público, 1924.

PARANÁ. Secretaria de Estado da Educação. Programas e Projetos Programa Saúde na Escola. Curitiba; SEED, 2017 Disponível em http://www.gestaoescolar.diaadia.pr.gov.br/modules/conteudo/conteudo.php?co nteudo $=175$. Acessado em 10 de out. 2017

PARANÁ. SECRETARIA DE ESTADO DA EDUCAÇÃO SEED. Programa Saúde na Escola. Curitiba: SEED, 2016 Disponível em http://www.educacao.pr.gov.br/modules/conteudo/conteudo.php?conteudo=304 . Acessado em 20/07/2016

PARANA. DIRETORIA GERAL DE ENSINO. Revista O Ensino anos 19201924. Curitiba: Diretoria Geral de Ensino, 1920, 1921a,1922a,1923a,1924a. Disponível na Biblioteca Pública do Paraná

CURTIBA. PREFEITURA MUNICIPAL DE CURITIBA. SECRETARIA MUNICIPAL DE EDUCAÇÃO. Programa Saúde na Escola -2017. Disponível em http://www.educacao.curitiba.pr.gov.br/conteudo/pse-programa-de-saudena-escola-2016/6457. Acessado em 10 de out 2017

BRASIL. Ministério da Saúde. Brasil registra menor número de casos de malária nos últimos 35 anos. DipoPARnível em http://portalsaude.saude.gov.br/index.php/cidadao/principal/agenciasaude/23368-brasil-registra-menor-numero-de-casos-de-malaria-nos-ultimos35-anos 